in Table XI., 2 were among those who had only had one prophylactic dose, and cannot be considered as immunised.

TABLE XI.-Analysis of the 34 Severe Cases (all Pneumonic) at Camp D.

\begin{tabular}{|c|c|c|c|}
\hline $\begin{array}{l}\text { Interval between inoculation } \\
\text { and infection. }\end{array}$ & $\begin{array}{l}\text { Number of } \\
\text { severe } \\
\text { cases. }\end{array}$ & Deaths. & $\begin{array}{c}\% \text { of } \\
\text { deaths to } \\
\text { severe cases. }\end{array}$ \\
\hline M.C.V. $\left\{\begin{array}{l}\text { Within first } 10 \text { days } \\
\text { Within second } 10 \text { days... }\end{array}\right.$ & 3 & $\frac{1}{1}$ & \} $33 \%$ \\
\hline$\underset{2}{\text { M.C.V. }}\left\{\begin{array}{l}\text { Within first } 10 \text { days } \\
\text { Within second } 10 \text { days } \ldots . .\end{array}\right.$ & $\begin{array}{l}17 \\
11\end{array}$ & $\begin{array}{l}4 \\
1\end{array}$ & \} $18 \%$ \\
\hline $\begin{array}{llllll}\ldots & \ldots & \ldots & \ldots & \ldots\end{array}$ & 34 & 7 & $20 \%$ \\
\hline
\end{tabular}

If the total mortality among serious cases in this inoculated camp be taken as it stands, the result, 20 per cent., compares very favourably with the mortality percentage among serious cases of 50 per cent. and 70 per cent. in noninoculated persons as occurred at Hospitals $A$ and $B$ (Table III. and Table VI.). If, however, as might be legitimately done, only the 5 cases who received the two prophylactic doses be considered as representing the mortality among the fully inoculated group (Table XI.), then the mortality among serious cases falls to 15 per cent.

There are also other factors to consider in this connexion. The men go to the convalescent depôt straight from hospitals, some more convalescent than others; the conditions of life usually become quickly more rigorous than those of the previous hospital existence. Again, many men are eventually drafted out as P.U. (permanently unfit), and therefore, although there are numbers of fit men in a convalescent camp of approximately 2500 , there are also many more men of a lower classification proportionately than in other camps.

Under these oircumstances prophylactic vaccination, which was in this unit undertaken comparatively early in the epidemic period, appears to have determined a better ultimate result than might have been expected from the experience of units where uninoculated persons became infected.

Prophylactic Vaccination in Presence of Epidemic.

One further point arises-namely, the question of the use of prophylactic vaccination in the presence of an epidemic. We consider the inference to be drawn from the experiences of camps $F, G$, and $J$ provides the basis for an answer to this question. Camp F continued inoculation throughout the epidemic period and combined vaccinal prophylaxis with personal hygiene-that is to say, whilst segregating definite cases in observation huts, treated every mild catarrh as an infective focus, and by antiseptic gargles and sprays, plus sterilisation of handkerchiefs and underclothing, endeavoured -efficiently in our opinion-to minimise the risk to the healthy individuals in the camp. At the same time no attempt was made to lower the vitality and resisting power of Nature's first line of defence-the surface cells of the mucous membrane of the upper respiratory tract-of the healthy, aninfected individuals; result, influenza incidence of only 3 per cent. of strength.

This appears to us to be the ideal method, and contrasts with that in Camp $G$, where vaccinal prophylaxis was discontinued and personal hygiene not carried out-result, an incidence of 36 per cent.; and Camp J, where vaccinal prophylaxis was completed and all was going well, when both healthy and presumably mild catarrhs were all sprayed, with the result that many of the previously apparently healthy (but possibly quiescent " carriers"), having had the macous membranes irritated by the spray and the surface cells devitalised, became active infections, so that the final incidence rate became $17 \cdot 2$ per cent.

References.-1. Fyre and Lowe: Prophylactic Vaccinations against Catarrhal Infections of the Respiratory Tract, THF LANCET, 1918, ii. 484. 2. Emery : The Practitioner, 1919, cii., 74. 3. Abrahame, Hallows, and French ; Trit LANoET, 1919, 1., 1. 4. Abrahams, Hallows, Eyre, and French : THE LANCET, 1917, i1., 377 .

THE Research Defence Society has moved its office to the House of the Medical Society of London, 11, Chandos-street, W.

Severe Diarrhgal OUTbreak in ABerdeen.-A few weeks ago an epidemic of a very severe diarrhceal nature broke out in Aberdeen. Several deaths occurred and over 1000 persons, both adults and children, were affected. Investigations pointed to a certain milk-supply which was stopped. Cases of secondary infection still occur, but are not of so severe a character. The precise nature of the malady has not so far been conclusively ascertained

\section{SOME POINTS IN THE TREATMENT OF COMPLICATED INFLUENZA.}

\author{
By A. J. EAGLETON, M.D. LOND., \\ CAPTAIN, R.A.M.C.; \\ AND \\ H. H. BUTCHER, M.R.C.S., L.R.C.P. LOND., \\ CAPTAIN, R.A.M.C.
}

THE following article deals more fully with the specific treatment advocated by us in THE LANCET of Dec. 7th, 1918. In view of the importance of the treatment of influenza at the present time, we have decided to publish the section on treatment before the remainder of the article.

\section{Treatment.}

In cases in which intense faucitis and glossitis followed, with difficulty in taking fluids, we used a mouth-wash of hydrogen peroxide and one of lotio. pot. permang., 1-4000 with $\mathrm{NaCl}$ alternately. To allow of nourishment a soft rubber tube passing back to the fances was fitted to a feeding-cup. The intercellular infusion of hot saline in septicæmic cases was tried in a few instances without result.

We began by giving all cases showing actual consolidation of the lung and all septicæmic cases antistreptococcic serum in small doses (10 c.cm.) as often as requisite; and where a secondary infection had not yet shown itself, we gave one prophylactic dose of $10 \mathrm{c.cm}$. In a number of cases of purulent bronchitis and broncho-pneumonia the serum seemed to have some value and the patients recovered, while in others of exactly the same type clinically, the method did not save the patient. The antistreptococcic serum used was that of Burroughs and Wellcome, the Lister Institute, and Mulford.

Then, when after the first autopsies we were certain that two varieties of secondary infection existed together or separately, we determined to try the value of a direct smear of the sputum as some indication of the nature of the infection. In a number of smears either innumerable Streptococous longus or enormous quantities of pneumococci were present, rarely the two together in anything like equal numbers. Meanwhile we had conceived the idea of preparing an antipneumococcal serum and a fresh complementary serum as described below. These sera had undoubted value.

To turn now to medicinal treatment. The terminal factor in most of our fatal cases was dilatation of the right heart with failure of the heart muscle, and our main effort was to lighten the strain upon this organ. The nursing staff did their all to prevent the patients moving in any way. The patients were propped up, with a donkey pillow beneath the knees to prevent slipping, and to ensure sleep and quietude we used morphia in adequate doses and combined with atropine; and the more cases in which this drug was used the more convinced we were of its value.

Next we treated a number of the cases from the start on tinct. strophanth., as adrocated by Major Elliot Dickson. These cases did well for the most part. The dose given was 5 minims of the B.P. tinct. strophanthi, and repeated every two hours ; even when the drug was given for some days on end we noticed no ill-effects. Digitalin was also given hypodermically in a series of cases without, in our opinion, much benefit. For those cases which were complicated by abdominal distension, due possibly to some toxæmic paresis of the bowel, we relied on spt. æth. co. and spt. cajuputi in ordinary doses and with good results. The laryngeal and tracheal symptoms were treated by mustard and linseed poultices locally and, in the first stages, by inhalations of tr. benzoin. We found an ordinary menthol inhalant useful when the condition was becoming subacute.

The majority of our patients are used to a certain amount of alcohol, and we prescribed this drug in practically every even moderately severe case. Another measure to which we attribute great importance is the nursing of these lung infections in the open air.

\section{Prophyiactic Vacination.}

We have made extensive use of vaccines with a view to prevention of catarrhal and pneumonic conditions. We have also in many cases carried out a routine prophylactic incculation of all cases suffering from measles with small doses of mixed vaccines containing $\mathcal{B}$. infuenze and other 
organisms-e.g., during June, 1918 : P.B. VIII., Streptococous longus, pneumococcus, $B$. influenzes, M. oatarrhalis 10 millions each per c.cm., $0.25,0.5$, and $1 \mathrm{c.cm}$. The small doses were used as we were in the presence of an epidemic. Previously we had been working with larger doses for prophylaxis only- e.g. : November, 1917, Br. 4, 2500 millions $B$. influenza, 500 millions Friedländer, dose 0.25 , followed by $0.5 \mathrm{c} . \mathrm{cm}$. But a prolonged negative phase had to be considered, and most of the newly arrived troops had slight catarrh. That the negative phase with the mixed catarrhal vaccine (Eyre and Lowe) is a definite factor has since been shown in the case of New Zealand troops. It has been difficult to obtain reliable figures, though what we have attest the value of such prophylactic inoculation.

The reactions were in no case severe, many hundred men being inoculated. One vaccine consisted of Streptocoecus longus, 4 millions, Pneumocosous, 6 millions, $B$. influenze, 1 million, $M$. eatarrhalis, 1 million per c.cm.; dose, $0.5 \mathrm{cccm}$., followed in ten days by $1 \mathrm{c.cm}$. This was given in May, 1918. Up to the end of July none of the 507 men who received two doses were taken to hospital or went sick in quarters. No negative phase was seen.

During the last three or four months the mixed catarrhal vaccine prepared by Dr. Eyre has been available in large quantities, and this has been used by the medical officers in charge of units in our area.

The object in prophylaxis was to immunise the troops against the organisms locally predominant. A very good general idea of the prevalence of various bacteria was obtained from study of the cultures made in the course of rontine swabbing for the meningococcus. Our vaccines were therefore varied to suit what we judged to be the local infection, and thus from October, 1917, till the present time we have prepared 12 stock mixtures all differing more or less. The organisms used were derived from the cultures above mentioned, post-mortem examinations, blood cultures, and cultivation of sputum of patients.

To show the variations in organisms at different times a return of sputum analysis from patients suffering from catarrhal and pulmonary diseases is given. This does not include sputa examined by direct methods without culture, and only the main organisms are given.

\begin{tabular}{|c|c|c|c|c|c|c|c|}
\hline 1918. & $\begin{array}{l}\text { No. } \\
\text { exa- } \\
\text { mined. }\end{array}$ & Pneum. & $\begin{array}{c}\text { Slaph. } \\
\text { aur. }\end{array}$ & $\begin{array}{c}B . \\
\text { Influen. }\end{array}$ & $\begin{array}{c}B . \\
\text { Fried. }\end{array}$ & $\begin{array}{l}\text { Strep. } \\
\text { long. }\end{array}$ & $\begin{array}{c}M . \\
\text { catarrh }\end{array}$ \\
\hline $\begin{array}{ll}\text { Jan. } & \ldots \\
\text { Feb. } & \ldots \\
\text { March } & \ldots\end{array}$ & 21 & 2 & 16 & 11 & 4 & 2 & 2 \\
\hline $\left.\begin{array}{ll}\text { Aprl1 } & \ldots \\
\text { May } & \ldots\end{array}\right\}$ & 20 & 11 & 13 & 3 & 4 & 10 & 4 \\
\hline June $\quad \ldots$ & 14 & 11 & 12 & 4 & 0 & 9 & 1 \\
\hline Sept. & 10 & 6 & 8 & 9 & 0 & 10 & 0 \\
\hline Oet, $\quad \ldots$ & 16 & 14 & 4 & 4 & 5 & 5 & 7 \\
\hline $\left.\begin{array}{c}\text { Nov. (two } \\
\text { weeks).... }\end{array}\right\}$ & 17 & 14 & 2 & 5 & 4 & 5 & 3 \\
\hline
\end{tabular}

We had, indeed, ample warning of the possibility of widespread influenzal disease. It is obvious that a knowledge of the local pathogenic bacteria infesting the human air passages is of paramount importance if epidemics of catarrhal disease are to be anticipated and checked at an early stage, and we see that the infection varies greatly in any one district. It might, perhaps, be maintained that all over England the changes in the bacterial flora might be coincident (or nearly so) in time.

From our experience in this district we believe that the throat organisms prevalent amongst the healthy population are the same as those found in cases of catarrhal and pulmonary disease in the same area, and that by a constant study of the former we may anticipate and check any increase of the latter. One cannot help thinking that if the same "prophylactic" care could be taken amongst the civil population as has been taken amongst the military the incidence of the disease could be effectively diminished and curative measures prepared.

Vaccine and Serum Treatment of Aotnal Cases.

In the treatment of actual cases our methods have been varied to suit changes in character of the infection. Thus at first the complication of influenza commonly met with was "more or less bronchitis with or without high pyrexia." Only the more serious of such cases filtered to the main hospital in the area. The S.M.O., A.I.F., Sutton Veny, very kindly lent us charts of 138 cases treated in the local camp hospital with vaccine P.B. VII. (B. influenzae and $M$. oatarrhalis of each 20 millions per c.cm.). $0.25 \mathrm{c.cm}$. was given as a first dose. "It seems fair to say that in the pure influenza the cases do not appear to have been influenced for good or bad; in the bronchitic cases improvement is noted in many instances."

A similar vaccine ("A") prepared in this laboratory was used in some of the cases quoted by Colonel W. Marshall Macdonald and others. It appears to have been of some benefit, but it was intended for prophylaxis, so that the dosage was relatively high. Such acute cases as reported in that article would be treated by us with serum in the manner about to be described.

In our own area the complications of influenza until recently were generally mild, in fact, suitable for vaccine treatment. We had, however, decided that, in any acute pulmonary or septicæmic complications of influenza, passive immunisation was likely to be of more benefit. We had already learnt that in the secondary infections following influenza or combined with it the important organisms are Streptocooous longus and pneumococcus, and as no pneumococcal serum was available we decided in acute cases to use antistreptococcal serum pending bacteriological diagnosis.

Thus, when in September one of us was sent to investigate and assist in the treatment of a group of septicamic and pulmonary cases at a New Zealand Hospital antistreptococcal serum was employed liberally, and in many cases with good results. The infection happened to be a suitable one (Streptococeus longus and $B$. influenza). Three different makes of serum were used and, where one variety failed, another seemed of benefit. In some of the less acute cases a vaccine prepared from the organisms derived from the blood and sputa was used in small doses (P.B. XII.) and patients in the same wards were prophylactically inoculated. From the end of September the streptococcal infections gradually got less frequent, with a rise in the pneumococcal.

\section{Antipnenmococoal Serum.}

Antibacterial sera can be produced, as is well known, by injecting organisms into animals not susceptible to theme.g., antimeningococcal serum (Gordon and others). It has also been used by Preston Kyes in the case of pneumococcus, and following his work we have attempted a rapid production of serum by inoculating domestic fowls with massive doses of pneumococci. At first the procedure was as follows: An intravenous inoculation was given on three consecutive days; on the fourth day a culture was taken from the blood, and, if no growth was obtained, the animal was bled on the fifth day. The blood invariably proved sterile. The serum obtained was sterilised by heating for 20 minutes at $60^{\circ}$.

We met with difficulties apart from the fact that fowls are scarce and expensive.

1. We had to produce a high antibody content with great rapidity. We had no means except animal experiment to test the value of the serum, the agglutinating power of a serum being no measure of therapeutic value. Only two experiments showed any great protective power in the serum. Several other experiments failed to elicit any power in the sernm to protect mice. We are still working on this point. The experimental work was meagre, but the rush of work has been tremendous. The severity and number of cases made us decide to give the serum a trial. At first only patients apparently moribund were selected. The results will be given later.

2. We found that the yield of serum from different bleedings varied enormously; it was hard to obtain the serum free from hæmolysis. In view of this fact, and also being unable to standardise the value of each separate collection of serum, we tried to arrive at a technique which should give uniform preparations. The following is the method now used:-

Two strains of pneumococci are employed for each fowl ; these have been recently isolated either from the blood or lung post mortem or from sputa of serious cases, and proved virulent for mice in small doses. Intraperitoneal injections (as recommended by Kyes) are given three times in one week. The dose is $10 \mathrm{c.cm}$. of an emulsion containing $12 \frac{1}{2}-20$ 
million per c.cm. (as measured by the vanishing point). The day after the third dose the fowl is bled by needling the heart ; this can be carried out by thrusting the needle boldly towards the heart from the episternal notch; should the operation be unsuccessful, the animal is killed by decapitation under an anæsthetic. 8 to $10 \mathrm{c.cm}$. of blood is obtained by needling and squirted into a sterile test-tube containing an equal amount of 1 per cent. sodium citrate in saline, and well mixed. This is stood in the dark in a cold cupboard till the next day, when the corpuscles will have sedimented completely. The supernatant fluid is removed and heated at $60^{\circ} \mathrm{C}$. for 20 minutes. The preparation so obtained is turbid and needs thorough shaking before use. We have, therefore, never given it intravenously. It is not a true serum, but a diluted blood plasma, containing in all probability dead pneumococci or their products. We have cultivated the blood when freshly withdrawn, but never obtained a growth of pneumococcus. At first we combined with this "plasma" fluid a vacoine (P.B. XII.), but probably the serum as prepared is of the nature of a sero-vaccine (comparable to Chantemesse's serum ?). A dose of $2-4 \mathrm{c.cm}$. is given.

\section{Fresh Complement.}

Any "complement" in the fowl's serum is lost in preparation. Moreover, fresh serum has been used in many diseases; the more recent the serum the better. We think it will be generally conceded that in all infectious diseases terminating fatally there must be an inadequate production of specific protective properties, and also an exhaustion of certain non-specific bodies or attributes of the blood serum ; these latter, we believe, could be supplied by the injection of absolutely fresh serum collected aseptically and not subjected to heating.

Guinea-pigs' serum contains a large amount of complement and probably other substances (or has other attributes) less easy of demonstration. We decided to use fresh guinea-pigs' serum both in combination with the antipneumococcal serum and alone. We speak of this fresh serum as " complement," though we do not say that this particular substance is the only active agent employed.

The method of preparation is very simple. The guineapig's blood is obtained by needling the heart; $8 \mathrm{c.cm}$. can be safely withdrawn. The blood is allowed to clot in the cold and the serum is collected the next day, diluted with three parts of sterile saline containing 0.5 per cent. carbolic and stored in a sterile rubber-capped dark-glassed bottle. It is generally used the same day, and never kept longer than 48 hours after collection. It is injected into the subcutaneous tissue of the abdomen in amounts of $4-10 \mathrm{c} . \mathrm{cm}$. If given with antipneumococcal or antistreptococcal serum it is mixed in the syringe prior to injection.

The chief danger is contamination during preparation, in spite of all precautions. We have, however, been giving an average of three or four injections a day to different patients for the last five or six weeks, and no untoward complications have occurred. As to the benefit conferred by its use in some cases we have little doubt. It should also be of value in all infectious conditions, and we trust that others will give it a trial.

References.-Adolphe Abrahams, Norman F. Hallows, J. W. H. Eyre, and Herbert French: Purulent Bronchitis, its Influenzal and Pneumococcal Bacteriology, The Lancet, 1917, ii., 377. Adolphe Abrahams, Norman Hallows, and Herbert French: A Further Investigation into Influenzo-pneumococcal and Influenzo-streptococcal Septicæmia. THE Larcht, 1919, i., 1. J. A. B. Hammond, William Rolland, and T. H. G. Shore: Purulent Bronchitis, a Study of Cases Occurring Amongst the British Troops at a Base in France. The Lancex, 1917, 1i., 41. D. H. Richey and C. Goebring: Studies on Bacteriemias in the Agonal Period, Journal Medical Research, July, 1918. D. Elliott Dickson : On the Treatment of Pneumonia, Brit. Med. Jour., Oct. 19th, 1918. P. Kyes : The Treatment of Lobar Pneumonin with an Antipneumococcal Serum, Journal Medical Research, July, 1918. Macdonald, Ritchie, Fux, and White : Purulent Bronchitis Complicating Measles and Rubella, Brit. Med. Jour., Nov. 2nd, 1918.

THE 2nd Southern General Hospital has been practically closed for the admission of patients. The base of the hospital is the King Edward VII. Memorial Wing of the Bristol Royal Infirmary. The sections and auxiliaries of the hospital brought the total of beds up to 5800, and at the close of 1918 the total number of patients who had passed through the 2nd Southern General Hospital was 86,000.-The Royal Naval Auxiliary Hospital, Truro, which was opened in January, 1916, is soon to be closed.

\section{Clinital oftotes:}

MEDICAL, SURGICAL, OBSTETRICAL, AND THERAPEUTICAL.

\author{
POLYORRHOMENITIS.
}

BY W. E. Cooke, M.D. LiverP., F.R.C.P. EdiN., D.P.H. LOND.,

TEMPORARY CAPTAIN, R.A.M.C.

Polyorrhomenitis, polyserositis, Concato's disease, or hyaloserositis is sufficiently uncommon to warrant the publication of this case.

The patient, aged 29, a Turkish corporal, was admitted to a P. of W. hospital on Jan. 16th, complaining of malaise, slight congh, and pains in back and sides of chest. He had been in the Army for some years prior to 1914. He had had no previous illness, and was always able to perform his duties. No family history of tuberculosis was elicited. Lifelong abstainer; no history or evidence of syphilis. I saw him on Feb. 5th. His condition was as follows: Temperature $98^{\circ}$ F., respirations 20 with slight dyspncea, pulse 88 -good volume and tension. He was slightly cyanosed; venules of cheeks prominent; conjunctivæ had subicteral tinge. There was marked epigastric pulsation. Hypertrophic pulmonary arthropathy was marked in the hands. Diastolic collapse of the cervical veins was not present; no paradoxical pulse.

Lungs: Chest expansion equal but porr. Litten's sign absent. Vocal fremitus very much diminished over both sides of chest. The percussion note was much impaired; in no region absolute flatness. On auscultation the breath sounds were faintly heard over lower three-fourths of chest. At the apices in front the breath sounds were more audible. Fxpiration was prolonged over whole chest; at bases were a few moist râles. Creaks were heard all over the chest. Sputum: Scanty, muco-purulent. No tubercle bacilli found; pneumococci present in abundance. Heart: The apex impulse could not be seen; marked epigastric pulsation; cervical veins not prominent. By palpation a diffuse very faint systolic impulse could be detected in fourth and fifth interspaces, inside nipple line. Percussion showed area of dullness from 2 inches on right of sternum to 4 inches on left, at level of fourth interspace. The dullness extended upwards to sternal notch, and laterally blended with impaired resonance over lungs. Auscultation: The heart sounds were faintly heard at the apex. The pulmonic second sound was very loud compared with the aortic. Crackling râles over whole of sternum and adjacent chest wall. Abdomen : The liver extended an inch below costal margin; no ascites. Urine: Sp. gr. 1018; no albumin, no sugar.

The patient appeared to progress favourably up to the night of Feb. 8th, when he had an attack of dyspnoea. The anhelation became extreme and he died on the morning of Feb. 9th, with all the signs of codema of the lungs.

Post-mortem.-The sternum and costal cartilages were firmly bound down by a fibrous tissue to the underlying structures. Extending from the superior mediastinum and invading the pleuro laterally was a dense mass of yellowish white glistening fibrous tissue. Where it had been separated from the anterior chest wall the tissue had a honercomb appearance. Pericardium : Could not be separated from the fibrous mass which covered it, in various thicknesses, from $l_{\frac{1}{2}}$ inches immediately behind sternum to $\frac{1}{2}$ inch at apex. On section the pericardium was thickened from $\frac{1}{8}$ inch to inch; inner surface presented smooth porcelain white appearance. No adhesions between peri- and epi-cardial layers. About one ounce of pericardial fluid. Heart The right ventricle was hypertrophied and dilated right auricle very distended. On surface of both auricles and ventricles were numerous white patches from inch square to 11 inches by inch. In thickness the larger milk spots were about inch in the centre gradually blending with the normal epicardium. The heart muscle appeared normal; no fibrous invasion from spots demonstrable. Lungs: Dense pleural adhesions extended from apex to base. In some of the interstices there was a small amount-a few drachms-of pale serous fluid. The parietal pleura was in places inch thick and of pearly white. When the lungs were freed they did not collapse to the usual dimensions. Surface dull, of a faint strawberry tint. The visceral pleura was appreciably thickened but allowed colour of lung to show through; slight puckerings. The puckerings seemed due to drawing in of pleura in attempt to collapse and not to fibrous invasion of lang tissue. On section there was very little pigmentation. 